\title{
Perspectives on Remorin Proteins, Membrane Rafts, and Their Role During Plant-Microbe Interactions
}

\author{
Iris K. Jarsch and Thomas Ott \\ University of Munich (LMU), Institute of Genetics, Großhaderner Str. 2-4, 82152 Planegg-Martinsried, Germany
}

Submitted 23 July 2010. Accepted 20 September 2010.

\begin{abstract}
Invasion of host cells by pathogenic or mutualistic microbes requires complex molecular dialogues that often determine host survival. Although several components of the underlying signaling cascades have recently been identified and characterized, our understanding of proteins that facilitate signal transduction or assemble signaling complexes is rather sparse. Our knowledge of plant-specific remorin proteins, annotated as proteins with unknown function, has recently advanced with respect to their involvement in hostmicrobe interactions. Current data demonstrating that a remorin protein restricts viral movement in tomato leaves and the importance of a symbiosis-specific remorin for bacterial infection of root nodules suggest that these proteins may serve such regulatory functions. Direct interactions of other remorins with a resistance protein in Arabidopsis thaliana, and differential phosphorylation upon perception of microbial-associated molecular patterns and during expression of bacterial effector proteins, strongly underline their roles in plant defense. Furthermore, the specific subcellular localization of remorins in plasma membrane microdomains now provides the opportunity to visualize membrane rafts in living plants cells. There, remorins may oligomerize and act as scaffold proteins during early signaling events. This review summarizes current knowledge of this protein family and the potential roles of remorins in membrane rafts.
\end{abstract}

Remorins are plant-specific proteins that comprise a multigene family in all land plants, including ferns and mosses (e.g., 16 members in Arabidopsis thaliana, 19 in Oryza sativa, four in Physcomitrella patens, and two in Welwitschia mirabilis). They have recently been divided into six distinct subgroups that are characterized by a highly conserved C-terminal region that harbors a coiled-coil domain and a set of conserved positively charged and aliphatic amino acid residues. In contrast, the N-terminal region is highly variable or absent in different remorins (group 3). Whereas group 1 remorins are abundantly expressed and characterized by a proline-rich $\mathrm{N}$-terminal region, no putative functional domains can be predicted bioinformatically in these proteins. However, different putative domains have been identified within the longer $\mathrm{N}$-terminal regions of group 6 remorins (Raffaele et al. 2007).

Originally, a remorin protein $(34-\mathrm{kDa}$ phosphorylated protein [pp34], now StREM1.3) that was shown to be associated with plasma membranes (PM) and to be phosphorylated upon

Corresponding author: Thomas Ott;

E-mail: Thomas.Ott@biologie.uni-muenchen.de treatment of potato leaves with polygalacturonic acid (PGA) (Farmer et al. 1989; Jacinto et al. 1993; Reymond et al. 1996) was suggested to play roles in cell-to-cell signaling and plant defense (Reymond et al. 1996). In vitro assays using soluble and microsomal protein fractions from PGA-treated leaves suggested phosphorylation by a PM-associated protein kinase (E. Farmer and P. Bariola, personal communication). This kinase could either be the intracellular kinase domain of the PGA receptor or another intracellular, membrane-bound kinase that is activated upon PGA recognition. Group 1 remorins were shown to bind oligogalacturonides and other polyanionic molecules, to form oligomeric filamentous structures in vitro, and to share structural similarities to viral movement proteins (Bariola et al. 2004; Farmer et al. 1989; Reymond et al. 1996). The ability to bind nucleic acids among other polyanionic molecules in vitro led to the annotation in several databases that remorins are DNA-binding proteins (Alliotte et al. 1989; Reymond et al. 1996). However, there is currently no in vivo evidence that this feature is biologically relevant.

\section{Remorins in membrane rafts.}

The term "membrane raft" has been established for PM domains that are composed of sterols and sphingolipids as well as proteins that are involved in the genesis and maintenance of these microdomains resulting in a tightly packed, liquid order phase membrane bilayer of less than $200 \mathrm{~nm}$ in diameter (Jacobson et al. 2007; Lingwood and Simons 2010; Pike et al. 2006). These rafts have a thickness of $4.6 \mathrm{~nm}$ compared with unordered phospholipid bilayers that are $4.0 \mathrm{~nm}$ thick (Risselada and Marrink 2008). They are characterized by their insolubility to nonionic detergents such as Triton-X-100 at low temperatures and, thus, were also named "detergent resistant membranes" (DRM). Biologically, membrane rafts have been suggested to serve as key platforms for signal transduction processes, bacterial and viral infection, cell division, apoptosis, adhesion, and chemotaxis (Duncan et al. 2002; Simons and Toomre 2000). Interestingly, it was shown that microtubules and F-actin are involved in endocytosis and recycling of PM subdomains in fibroblasts (Balasubramanian et al. 2007) and in plant cells (Grebe et al. 2003), providing a putative link between other cell organelles, the cytoskeleton (such as the nucleus and plastids), and membrane rafts.

Although most of the pioneer work has been performed in mammalian cells and yeast, there is also clear evidence for the existence of sterol- and sphingolipid-rich membrane fractions in plants (Bhat et al. 2005; Borner et al. 2005; Kierszniowska et al. 2009; Laloi et al. 2007; Minami et al. 2009; Mongrand et al. 2004; Morel et al. 2006; Raffaele et al. 2009; Sorek et al. 2007). Visualization of plant membrane rafts has been restricted, 
thus far, to the use of dyes such as the UV-excitable antibiotic filipin. Accumulations of filipin-stainable PM subdomains have been shown in barley during appressorium formation and along appressorial germ tubes formed by the powdery mildew fungus Blumeria graminis formae specialis. (Bhat et al. 2005), indicating a possible involvement of membrane rafts during fungal infections. However, no direct evidence showing that these domains are, indeed, membrane rafts has been provided thus far. Due to its photo-instability, filipin is a difficult dye to work with in thick tissues and, thus, limited in vivo analysis of these domains mostly to epidermal cell layers. Identification and expression of fluorophore-tagged in vivo markers would allow the discrimination between sterol-rich PM domains and the remaining unordered liquid phase membrane area. In plants, remorin proteins are highly enriched in DRM (Kierszniowska et al. 2009; Laloi et al. 2007; Lefebvre et al. 2007, 2010; Mongrand et al. 2004; Morel et al. 2006; Raffaele et al. 2009). Although remorins are preferentially targeted to DRM, as shown when purified PM were treated with methyl- $\beta$-cyclodextrin (m $\beta C D)$, a chelator of free sterols, they seem to be able to also associate with sole phospholipids bilayers because the total amount of remorin protein was not altered in DRM fractions that were treated with $\mathrm{m} \beta \mathrm{CD}$ and the protein remained in the microsomal fraction despite sterol depletion (Raffaele et al. 2009).

Immunolocalization of NtREM1.2 from tobacco revealed that the protein almost exclusively accumulates in isolated DRM that were inspected by electron microscopy. These accumulations were disrupted when DRM were treated with $\mathrm{m} \beta \mathrm{CD}$, demonstrating the dependency of remorin clustering on the presence of sterols. Moreover, NtREM1.2 was shown to localize to distinct domains in the PM when being expressed as a green fluorescent protein fusion protein in tobacco leaves (Raffaele et al. 2009). These experiments demonstrated that remorins (at least members of the subgroup 1b) are the first real marker proteins for such DRM in plants and, therefore, will serve as a valuable tool to visualize compartmentalization of plant PM (Raffaele et al. 2009). Raft distribution on the cell surface is cell-type specific but may also be dependent on external stimuli and developmental stages (Simons and Toomre 2000).

Anchoring of proteins to membrane rafts has been mainly suggested to occur via glycosylphosphatidylinositol (GPI) anchors, C-terminal posttranslational glycolipid modifications. Indeed, proteomic analyses of isolated membrane rafts yielded the identification of a whole array of GPI-anchored proteins (Brown and Rose 1992; Kierszniowska et al. 2009; Schnitzer et al. 1995), and putative rafts were visualized when localizing the GPI-anchored folate receptor in punctuated structures on the PM of adipose 3T3L1 cells (Mayor et al. 1994). Other protein modifications such as palmitoylation and double acetylation, as well as certain regions of transmembrane domains that increase the affinity of proteins to membrane rafts, have been described for eukaryotic cells (Melkonian et al. 1999; Scheiffele et al. 1997). Remorins do not contain any predictable transmembrane domains or GPI anchor sequences, while palmitoylation of the proteins cannot be excluded. However, palmitoylation alone is rather unlikely to be sufficient to anchor the proteins to the PM but may serve as an auxiliary system. The mechanism that is used by remorins to anchor to the PM and to specifically localize to membrane rafts is currently under investigation. However, the fact that remorins form higher order oligomers may also have an impact on their binding affinity to membrane rafts.

\section{Involvement of remorins in controlling host invasion.}

Membrane rafts have been demonstrated to serve as a key entry site for microbes and viruses in mammalian cells (Hartlova et al. 2010; Manes et al. 2003b). Although similarities to viral movement proteins had been suggested for group $1 \mathrm{~b}$ remorins earlier (Reymond et al. 1996), it has only recently been demonstrated that overexpression of a remorin from tomato (SIREM1.3) inhibited movement of Potato virus $X$ in leaves (Raffaele et al. 2009). This is supported by direct interaction of this remorin with the viral protein TGBp1 and its localization in plasmodesmata that serve as cytoplasmatic cell-to-cell bridges in plants and are used by viruses to spread throughout the host tissue (Raffaele et al. 2009).

Further evidence for the involvement of remorins in plant infection pathways has recently been provided for a remorin protein from the legume Medicago truncatula (Lefebvre et al. 2010) that belongs to another remorin subgroup (group 2; MtREM2.2), which is exclusively found in plants of the rosid clade (Raffaele et al. 2007). This membrane-raft-associated remorin protein (MtSYMREM1) was shown to be specifically induced during root nodule symbiosis, where bacteria belonging to the Rhizobiaceae family infect their host plants via infection threads (IT) and drive the formation of a root nodule (Lefebvre et al. 2010). In this newly formed plant organ, bacteria are released into the cytoplasm of host cells, where they remain surrounded by a plant-derived PM (symbiosome membrane). Differentiation of the bacteria leads to the development of bacteroids that are able to fix atmospheric nitrogen that is subsequently delivered to the host plant (Den Herder and Parniske 2009). Root infection and formation of functional root nodules are impaired in plants that lack MtSYMREM1, demonstrating the importance of this remorin protein during bacterial infection. The protein itself localizes to IT membranes in the infection zone of a root nodule and to symbiosome membranes throughout the symbiotic interaction. If membrane rafts are present on IT membranes, and to what extent proteins are specifically recruited to these microdomains during infection, remain challenging questions.

Strong accumulation of MtSYMREM1 has also been shown at sites where rhizobia are released into the host cytosol (Lefebvre et al. 2010). The physiological nature of this process is still not fully understood but accumulation of the syntaxin SYP132 at these release sites argued for an endocytotic process driving bacterial release (Catalano et al. 2007). Results from a recent study imply that a modified endocytotic program is required for bacterial release from the IT because classical late endosomal markers such as the small GTPase Rab5 and the vacuolar SNARE SYP22 were found on release sites and symbiosome membranes in $M$. truncatula. However, accumulations of another small GTPase Rab7 as well as the SNARE SYP132 on the symbiosome membrane and on endocytotic vesicles in infected cells suggest that symbiosomes appear to be locked in a unique SYP132- and Rab7-positive stage (Limpens et al. 2009). Interestingly, a SYP132 protein from Arabidopsis thaliana is recruited to filipin-sensitive membrane regions when cells were attacked by pathogenic powdery mildew, indicating putative localization of SYP132 to membrane rafts (Bhat et al. 2005).

We demonstrated that the nodulation-induced remorin protein MtSYMREM1 interacts with at least the three receptorlike kinases (RLK) NFP, LYK3, and DMI2 that are essential for root nodule symbiosis (Lefebvre et al. 2010). Although the two LysM-RLK NFP and LYK3 in M. truncatula and NFR1 and NFR5 in Lotus japonicus have been proposed to recognize the bacterial signaling molecule, the Nod factor (Arrighi et al. 2006; Limpens et al. 2003; Madsen et al. 2003; Radutoiu et al. 2003), the roles of the leucine-rich repeat (LRR)-RLK DMI2 (Medicago spp.) (Endre et al. 2002) and SYMRK (Lotus spp.) (Stracke et al. 2002) remain to be solved. Recent data strongly suggest the presence of NFP, LYK3, and DMI2 in both early 
(root hair responses) and later (nodule infection and bacterial release) stages of symbiotic interactions because all three RLK are involved in IT initiation and progression and are expressed specifically in a nodule zone where bacteria continuously infect the host plant (Arrighi et al. 2006; Limpens et al. 2003, 2005). Although the above-mentioned LysM-RLK are only required for root nodule symbiosis, loss of DMI2 and SYMRK additionally leads to the inability of the plant to undergo arbuscular mycorrhiza (AM) symbiosis as well as root nodule symbiosis. During the course of this ancient symbiosis, the AM fungus remains surrounded by a plant-derived PM and forms arbuscules that serve as an active surface for nutrient exchange between the host plant and the AM fungus (Parniske 2008). Another group 2 remorin is strongly induced during AM symbiosis but the biological role of this protein remains to be studied in detail (Kistner et al. 2005).

Despite the identification of several LRR- and LysM-type RLK in DRM of M. truncatula (Lefebvre et al. 2007), the question of whether any of the symbiotic RLK localize to membrane rafts has not yet been studied. However, it is also possible that proteins such as remorins transiently recruit these RLK into rafts.

Interestingly, data for several flotillin proteins that are also involved in regulation of rhizobial invasion in legumes have recently been presented (Haney and Long 2010). Two members of this protein family (FLOT2 and FLOT4) accumulate in punctuated foci while only FLOT4 relocalizes to the tip of root hairs upon inoculation of Medicago roots with symbiotic Sinorhizobium meliloti (Haney and Long 2010). Flotillins (Reggie proteins) have been described in almost all taxa, including plants. However, due to low sequence similarities, it remains uncertain whether they originate from a common ancestor. Flotillins are membrane-associated proteins that either loop into the PM bilayer or anchor to the PM by myristoylation and palmitoylation (Babuke and Tikkanen 2007). Although the function of these proteins remains to be elucidated, they have been numerously suggested to be associated with various signaling processes via membrane receptors, with raft-mediated endocytosis and phagocytosis, and with the regulation of the cytoskeleton and neurite outgrowth (Baumann et al. 2000; Dermine et al. 2001; Glebov et al. 2006; Hazarika et al. 2004; Lang et al. 1998; Neumann-Giesen et al. 2004, NeumannGiesen et al. 2007; Schulte et al. 1997), where they might function as scaffold proteins (Langhorst et al. 2005; Morrow and Parton 2005). The question of whether remorins and FLOT localize to the same microdomains and share functional features that are required for host infection remains to be studied.

There is further accumulating evidence that other members of the remorin protein family are involved in plant-microbe interactions because several remorins are differentially regulated during host invasion by pathogenic bacteria. Primarily group $1 \mathrm{~b}$ remorins were reported to be differentially regulated in A. thaliana upon infection with Pseudomonas syringae (Nelson et al. 2006; Widjaja et al. 2009) as well as after inoculation of Lycopersicum hirsutum with Clavibacter michiganensis (Coaker et al. 2004). Plants perceive pathogenic bacteria and fungi by pattern recognition receptors that recognize pathogen-associated molecular patterns (PAMPs) or microbial-associated molecular patterns (MAMPs), basal molecular patterns associated with whole classes of microbes (Altenbach and Robatzek 2007; Bittel and Robatzek 2007 Boller and Felix 2009; Nürnberger and Kemmerling 2006). For example, wellcharacterized MAMPs are flagellin as a component of the bacterial flagellum (Felix et al. 1999; Gomez-Gomez et al. 1999) or the bacterial elongation factor EF-Tu (Kunze et al. 2004; Zipfel et al. 2006). Several of the RLK involved in MAMP perception have been characterized. The LRR-RLK FLS2 and
EFR recognize flg22 and EF-Tu, respectively, while the LysMtype RLK CERK1 binds fungal chitin molecules (Chinchilla et al. 2006; Heese et al. 2007; Miya et al. 2007; Zipfel et al. 2006).

In a large-scale proteomic approach to identify differentially phosphorylated proteins involved in early MAMP signaling after treatment with flg22 and fungal xylanase, AtREM1.3 was phosphorylated in an flg22-dependent manner. Interestingly, phosphopeptides of remorins AtREM1.2, AtREM5.1, AtREM6.1, AtREM6.2, and AtREM6.4 were detected; however, there was no significant difference in phosphorylation status compared with mock-treatment (Benschop et al. 2007). Questions of whether FLS2 phosphorylates AtREM1.3 directly and whether this protein is involved in dynamic relocalizations of FLS2 such as flg22-triggered endocytosis of the receptor (Robatzek et al. 2006) remain to be studied.

Successful pathogens inject effector proteins via their typeIII secretion system into the host cell, targeting essential components of the plant innate immune system which, consequently, results in effector-triggered susceptibility (Göhre and Robatzek 2008). Interestingly, it was recently shown that injection of some effector proteins belonging to the RxLR class into host cells is dependent on the presence of phosphoinositol-3-phosphate on the cell surface (Kale et al. 2010). Accordingly, polyphosphoinositides have been demonstrated to be an integral component of membrane rafts in plants (Furt et al. 2010), strengthening putative roles of membrane rafts during pathogen attack. In response to effector injection, plants have added a second layer of plant innate immunity based on intracellular components, mostly nucleotide-binding (NB)-LRR-type proteins encoded by so-called resistance $(R)$ genes (Meyers et al. 2003). These proteins indirectly recognize pathogen effectors delivered inside host cells during infection, resulting in effector-triggered immunity (ETI). In susceptible plant genotypes, effectors enhance pathogen virulence and can inhibit PAMP-triggered immunity (PTI) and ETI, whereas effectors are recognized in resistant plant genotypes, leading to the inhibition of pathogen growth (Jones and Dangl 2006). Involvement of remorins in ETI has been suggested because AtREM1.2 is significantly upregulated in an RPM1-dependent manner in plants overexpressing the bacterial effector AvrRPM1. Additional isoforms of the protein were found in the induced state, indicating differential phosphorylation of AtREM1.2 dependent on the interaction between AvrRPM1 and the corresponding $R$ protein RPM1 (Widjaja et al. 2009). Furthermore, it was reported that AtREM1.2 interacts with RIN4 (Liu et al. 2009), a 211-aminoacid, acylated, and PM-associated protein that is involved in both PTI and ETI (Kim et al. 2005b). Being targeted by several $P$. syringae effector proteins, RIN4 is the paradigmatic example for a host target that is guarded by NB-LRR resistance proteins. Two different type III effectors, AvrRpm1 and AvrB, interact with RIN4 and induce hyperphosphorylation, which leads to RPM1-mediated resistance (Mackey et al. 2002). A third effector, AvrRpt2, a cysteine protease (Axtell et al. 2003; Kim et al. 2005a) that is activated inside the host cell (Coaker et al. 2005), directly targets RIN4. The possibility that remorins may be targets of bacterial effectors themselves is likely. Indeed, a putative target sequence of avrRpt 2 in AtREM6.1 has already been published (Chisholm et al. 2005). However, this in silico prediction remains to be proven experimentally.

\section{Are remorins serving scaffolding functions in plants?}

The existence of scaffold proteins that preassemble signaling complexes has been suggested in different biological systems. A common feature of scaffold proteins is their ability to regulate signal transduction processes and, most often, to localize signaling components to certain cellular compartments such 
as the PM, the cytoplasm, the nucleus, the Golgi, the mitochondria, or endosomal structures (Shaw and Filbert 2009).

We currently hypothesize that at least some remorins may function as scaffold proteins that are able to recruit PM-associated and cytoplasmatic proteins into these microdomains to preassemble signaling complexes. Examples of such proteins have been reported mainly from human cells. A well-studied example of scaffold proteins in animals is the Homer protein family that comprises three members in humans, whereas only one Homer gene has been described in Drosophila melanogaster. Interestingly, several isoforms that result from alternative splicing have been described for the three human genes, resulting in a great diversity of Homer proteins in human nervous cells (Klugmann et al. 2005; Saito et al. 2002; Soloviev et al. 2000; Xiao et al. 1998). Homer interacts with a whole panel of membrane-resident and cytosolic proteins, giving rise to functional diversity of this protein family (Foa and Gasperini 2009). Among these proteins are the glutamate, NMDA, and $\alpha$-amino-3-hydroxy-5-methylisoxazole-4-propionate receptors. Whereas Homer 1b/c proteins physically interact with only the glutamate receptor, they interconnect and recruit these proteins into close proximity to each other by interacting with some of their downstream targets such as dynamin3, PSD95, and SHANK, leading to the assembly of a functional signaling complex (Lu et al. 2007). Remorins may act similarly to these scaffold proteins and may recruit different signaling and membrane modifying proteins into membrane rafts. Although roles in signal transduction during plant-microbe interactions are strongly supported by current data, their direct modes of action remain to be solved using genetic and cell-biological approaches. Nevertheless, a certain degree of functional redundancy appears to be likely (unpublished data) and will be a challenging aspect of uncovering their functions.

\section{LITERATURE CITED}

Alliotte, T., Tiré, C., Engler, G., Peleman, J., Caplan, A., Van Montagu, M., and Inzé, D. 1989. An auxin-regulated gene of Arabidopsis thaliana encodes a DNA-binding protein. Plant Physiol. 89:743-752.

Altenbach, D., and Robatzek, S. 2007. Pattern recognition receptors: From the cell surface to intracellular dynamics. Mol. Plant-Microbe Interact. 20:1031-1039.

Arrighi, J.-F., Barre, A., Ben Amor, B., Bersoult, A., Soriano, L. C., Mirabella, R., de Carvalho-Niebel, F., Journet, E.-P., Ghérardi, M., Huguet, T., Geurts, R., Dénarié, J., Rougé, P., and Gough, C. 2006. The Medicago truncatula lysin motif-receptor-like kinase gene family includes NFP and new nodule-expressed genes. Plant Physiol. 142:265279.

Axtell, M. J., Chisholm, S. T., Dahlbeck, D., and Staskawicz, B. J. 2003. Genetic and molecular evidence that the Pseudomonas syringae type III effector protein AvrRpt2 is a cysteine protease. Mol. Microbiol. 49:1537-1546.

Babuke, T., and Tikkanen, R. 2007. Dissecting the molecular function of reggie/flotillin proteins. Eur. J. Cell Biol. 86:525-532.

Balasubramanian, N., Scott, D. W., Castle, J. D., Casanova, J. E., and Schwartz, M. A. 2007. Arf6 and microtubules in adhesion-dependent trafficking of lipid rafts. Nat. Cell Biol. 9:1381-1391.

Bariola, P. A., Retelska, D., Stasiak, A., Kammerer, R. A., Fleming, A., Hijri, M., Frank, S., and Farmer, E. E. 2004. Remorins form a novel family of coiled coil-forming oligomeric and filamentous proteins associated with apical, vascular and embryonic tissues in plants. Plant Mol. Biol. 55:579-594.

Baumann, C. A., Ribon, V., Kanzaki, M., Thurmond, D. C., Mora, S., Shigematsu, S., Bickel, P. E., Pessin, J. E., and Saltiel, A. R. 2000. CAP defines a second signalling pathway required for insulin-stimulated glucose transport. Nature 407:202-207.

Benschop, J. J., Mohammed, S., O'Flaherty, M., Heck, A. J. R., Slijper, M., and Menke, F. L. H. 2007. Quantitative phosphoproteomics of early elicitor signaling in Arabidopsis. Mol. Cell Prot. 6:1198-1214.

Bhat, R. A., Miklis, M., Schmelzer, E., Schulze-Lefert, P., and Panstruga, R. 2005. Recruitment and interaction dynamics of plant penetration resistance components in a plasma membrane microdomain. Proc. Natl. Acad. Sci. U.S.A. 102:3135-3140.
Bittel, P., and Robatzek, S. 2007. Microbe-associated molecular patterns (MAMPs) probe plant immunity. Curr. Opin. Plant Biol. 10:335-341.

Boller, T., and Felix, G. 2009. A renaissance of elicitors: Perception of microbe-associated molecular patterns and danger signals by pattern-recognition receptors. Annu. Rev. Plant Biol. 60:379-406.

Borner, G. H. H., Sherrier, D. J., Weimar, T., Michaelson, L. V., Hawkins, N. D., Macaskill, A., Napier, J. A., Beale, M. H., Lilley, K. S., and Dupree, P. 2005. Analysis of detergent-resistant membranes in Arabidopsis. Evidence for plasma membrane lipid rafts. Plant Physiol. 137:104-116.

Brown, D. A., and Rose, J. K. 1992. Sorting of GPI-anchored proteins to glycolipid-enriched membrane subdomains during transport to the apical cell surface. Cell 68:533-544.

Catalano, C. M., Czymmek, K. J., Gann, J. G., and Sherrier, D. J. 2007. Medicago truncatula syntaxin SYP132 defines the symbiosome membrane and infection droplet membrane in root nodules. Planta 225:541550.

Chinchilla, D., Bauer, Z., Regenass, M., Boller, T., and Felix, G. 2006. The Arabidopsis receptor kinase FLS2 binds flg22 and determines the specificity of flagellin perception. Plant Cell 18:465-476.

Chisholm, S. T., Dahlbeck, D., Krishnamurthy, N., Day, B., Sjolander, K., and Staskawicz, B. J. 2005. Molecular characterization of proteolytic cleavage sites of the Pseudomonas syringae effector AvrRpt2. Proc. Natl. Acad. Sci. U.S.A. 102:2087-2092.

Coaker, G. L., Willard, B., Kinter, M., Stockinger, E. J., and Francis, D. M. 2004. Proteomic analysis of resistance mediated by Rcm 2.0 and $\mathrm{Rcm} 5.1$, two loci controlling resistance to bacterial canker of tomato. Mol. Plant-Microbe Interact. 17:1019-1028.

Coaker, G., Falick, A., and Staskawicz, B. 2005. Activation of a phytopathogenic bacterial effector protein by a eukaryotic cyclophilin. Science 308:548-550

Den Herder, G., and Parniske, M. 2009. The unbearable naivety of legumes in symbiosis. Curr. Opin. Plant Biol. 12:491-499.

Dermine, J. F., Duclos, S., Garin, J., St-Louis, F., Rea, S., Parton, R. G., and Desjardins, M. 2001. Flotillin-1-enriched lipid raft domains accumulate on maturing phagosomes. J. Biol. Chem. 276:18507-18512.

Duncan, M. J., Shin, J.-S., and Abraham, S. N. 2002. Microbial entry through caveolae: Variations on a theme. Cell Microbiol. 4:783-791.

Endre, G., Kereszt, A., Kevei, Z., Mihacea, S., Kaló, P., and Kiss, G. B. 2002. A receptor kinase gene regulating symbiotic nodule development. Nature 417:962-966.

Farmer, E. E., Pearce, G., and Ryan, C. A. 1989. In vitro phosphorylation of plant plasma membrane proteins in response to the proteinase inhibitor inducing factor. Proc. Natl. Acad. Sci. U.S.A. 86:1539-1542.

Felix, G., Duran, J. D., Volko, S., and Boller, T. 1999. Plants have a sensitive perception system for the most conserved domain of bacterial flagellin. Plant J. 18:265-276.

Foa, L., and Gasperini, R. 2009. Developmental roles for Homer: More than just a pretty scaffold. J. Neurochem. 108:1-10.

Furt, F., König, S., Bessoule, J. J., Sargueil F., Zallot, R., Stanislas, T., Noirot, E., Lherminier, J., Simon-Plas, F., Heilmann, I., and Mongrand, S. 2010. Polyphosphoinositides are enriched in plant membrane rafts and form microdomains in the plasma membrane. Plant Physiol. 152:2173-2187.

Glebov, O. O., Bright, N. A., and Nichols, B. J. 2006. Flotillin-1 defines a clathrin-independent endocytic pathway in mammalian cells. Nat. Cell Biol. 8:46-54.

Göhre, V., and Robatzek, S. 2008. Breaking the barriers: Microbial effector molecules subvert plant immunity. Annu. Rev. Phytopathol. 46:189215.

Gomez-Gomez, L., Felix, G., and Boller, T. 1999. A single locus determines sensitivity to bacterial flagellin in Arabidopsis thaliana. Plant $\mathbf{J}$ $18: 277-284$.

Grebe, M., Xu, J., Möbius, W., Ueda, T., Nakano, A., Geuze, H. J., Rook, M. B., and Scheres, B. 2003. Arabidopsis sterol endocytosis involves actin-mediated trafficking via ARA6-positive early endosomes. Curr. Biol. 13:1378-1387.

Haney, C. H., and Long, S. R. 2010. Plant flotillins are required for infection by nitrogen-fixing bacteria. Proc. Natl. Acad. Sci. U.S.A. 107:478 483.

Hartlova, A., Cerveny, L., Hubalek, M., Krocova, Z., and Stulik, J. 2010. Membrane rafts: A potential gateway for bacterial entry into host cells Microbiol. Immunol. 54:237-245.

Hazarika, P., McCarty, M. F., Prieto, V. G., George, S., Babu, D., Koul, D., Bar-Eli, M., and Duvic, M. 2004. Up-regulation of Flotillin-2 is associated with melanoma progression and modulates expression of the thrombin receptor protease activated receptor 1. Cancer Res. 64:73617369.

Heese, A., Hann, D. R., Gimenez-Ibanez, S., Jones, A. M. E., He, K., Li, J., Schroeder, J. I., Peck, S. C., and Rathjen, J. P. 2007. The receptor- 
like kinase SERK3/BAK1 is a central regulator of innate immunity in plants. Proc. Natl. Acad. Sci. U.S.A. 104:12217-12222.

Jacinto, T., Farmer, E. E., and Ryan, C. A. 1993. Purification of potato leaf plasma membrane protein pp34, a protein phosphorylated in response to oligogalacturonide signals for defense and development. Plant Physiol. 103:1393-1397.

Jacobson, K., Mouritsen, O. G., and Anderson, R. G. W. 2007. Lipid rafts: At a crossroad between cell biology and physics. Nat. Cell Biol. 9:7-14.

Jones, J. D. G., and Dangl, J. L. 2006. The plant immune system. Nature 444:323-329

Kale, S. D., Gu, B., Capelluto, D. G., Dou, D., Feldman, E., Rumore, A., Arredondo, F. D., Hanlon, R., Fudal, I., Rouxel, T., Lawrence, C. B., Shan, W., and Tyler, B. M. 2010. External lipid PI3P mediates entry of eukaryotic pathogen effectors into plant and animal host cells. Cell 142:284-295.

Kierszniowska, S., Seiwert, B., and Schulze, W. X. 2009. Definition of Arabidopsis sterol-rich membrane microdomains by differential treatment with methyl-beta-cyclodextrin and quantitative proteomics. Mol. Cell Prot. 8:612-623.

Kim, H.-S., Desveaux, D., Singer, A. U., Patel, P., Sondek, J., and Dangl, J. L. 2005a. The Pseudomonas syringae effector AvrRpt 2 cleaves its Cterminally acylated target, RIN4, from Arabidopsis membranes to block RPM1 activation. Proc. Natl. Acad. Sci. U.S.A. 102:6496-6501.

Kim, M. G., da Cunha, L., McFall, A. J., Belkhadir, Y., DebRoy, S., Dangl, J. L., and Mackey, D. 2005b. Two Pseudomonas syringae type III effectors inhibit RIN4-regulated basal defense in Arabidopsis. Cell 121:749759

Kistner, C., Winzer, T., Pitzschke, A., Mulder, L., Sato, S., Kaneko, T., Tabata, S., Sandal, N., Stougaard, J., Webb, K. J., Szczyglowski, K., and Parniske, M. 2005. Seven Lotus japonicus genes required for transcriptional reprogramming of the root during fungal and bacterial symbiosis. Plant Cell 17:2217-2229.

Klugmann, M., Symes, C. W., Leichtlein, C. B., Klaussner, B. K., Dunning, J., Fong, D., Young, D., and During, M. J. 2005. AAV-mediated hippocampal expression of short and long Homer 1 proteins differentially affect cognition and seizure activity in adult rats. Mol. Cell Neurosci. 28:347-360.

Kunze, G., Zipfel, C., Robatzek, S., Niehaus, K., Boller, T., and Felix, G. 2004. The $\mathrm{N}$ terminus of bacterial elongation factor $\mathrm{Tu}$ elicits innate immunity in Arabidopsis plants. Plant Cell 16:3496-3507.

Laloi, M., Perret, A.-M., Chatre, L., Melser, S., Cantrel, C., Vaultier, M.N., Zachowski, A., Bathany, K., Schmitter, J.-M., Vallet, M., Lessire, R., Hartmann, M.-A., and Moreau, P. 2007. Insights into the role of specific lipids in the formation and delivery of lipid microdomains to the plasma membrane of plant cells. Plant Physiol. 143:461-472.

Lang, D. M., Lommel, S., Jung, M., Ankerhold, R., Petrausch, B., Laessing, U., Wiechers, M. F., Plattner, H., and Stuermer, C. A. 1998. Identification of reggie-1 and reggie-2 as plasmamembrane-associated proteins which cocluster with activated GPI-anchored cell adhesion molecules in non-caveolar micropatches in neurons. J. Neurobiol. 37:502-523

Langhorst, M. F., Reuter, A., and Stuermer, C. A. O. 2005. Scaffolding microdomains and beyond: The function of reggie/flotillin proteins. Cell. Mol. Life Sci. 62:2228-2240.

Lefebvre, B., Furt, F., Hartmann, M.-A., Michaelson, L. V., Carde, J.-P., Sargueil-Boiron, F., Rossignol, M., Napier, J. A., Cullimore, J., Bessoule, J.-J., and Mongrand, S. 2007. Characterization of lipid rafts from Medicago truncatula root plasma membranes: A proteomic study reveals the presence of a raft-associated redox system. Plant Physiol. 144:402-418.

Lefebvre, B., Timmers, T., Mbengue, M., Moreau, S., Hervé, C., Tóth, K., Bittencourt-Silvestre, J., Klaus, D., Deslandes, L., Godiard, L., Murray, J. D., Udvardi, M. K., Raffaele, S., Mongrand, S., Cullimore, J., Gamas, P., Niebel, A., and Ott, T. 2010. A remorin protein interacts with symbiotic receptors and regulates bacterial infection. Proc. Natl. Acad. Sci. U.S.A. 107:2343-2348.

Limpens, E., Franken, C., Smit, P., Willemse, J., Bisseling, T., and Geurts, R. 2003. LysM domain receptor kinases regulating rhizobial Nod factor-induced infection. Science 302:630-633.

Limpens, E., Mirabella, R., Fedorova, E., Franken, C., Franssen, H., Bisseling, T., and Geurts, R. 2005. Formation of organelle-like $\mathrm{N}_{2}$-fixing symbiosomes in legume root nodules is controlled by DMI2. Proc. Natl. Acad. Sci. U.S.A. 102:10375-10380.

Limpens, E., Ivanov, S., van Esse, W., Voets, G., Fedorova, E., and Bisseling, T. 2009. Medicago $\mathrm{N}_{2}$-fixing symbiosomes acquire the endocytic identity marker Rab7 but delay the acquisition of vacuolar identity. Plant Cell 21:2811-2828.

Lingwood, D., and Simons, K. 2010. Lipid rafts as a membrane-organizing principle. Science 327:46-50.

Liu, J., Elmore, J. M., Fuglsang, A. T., Palmgren, M. G., Staskawicz, B. J., and Coaker, G. 2009. RIN4 functions with plasma membrane H+ATPases to regulate stomatal apertures during pathogen attack. PLoS Biol. 7:e1000139.

Lu, J., Helton, T. D., Blanpied, T. A., Racz, B., Newpher, T. M., Weinberg, R. J., and Ehlers, M. D. 2007. Postsynaptic positioning of endocytic zones and AMPA receptor cycling by physical coupling of dynamin-3 to Homer. Neuron 55:874-889.

Mackey, D., Holt, B. F., Wiig, A., and Dangl, J. L. 2002. RIN4 interacts with Pseudomonas syringae type III effector molecules and is required for RPM1-mediated resistance in Arabidopsis. Cell 108:743-754.

Madsen, E. B., Madsen, L. H., Radutoiu, S., Olbryt, M., Rakwalska, M. Szczyglowski, K., Sato, S., Kaneko, T., Tabata, S., Sandal, N., and Stougaard, J. 2003. A receptor kinase gene of the LysM type is involved in legume perception of rhizobial signals. Nature 425:637-640.

Manes, S., del Real, G., and Martinez, A. C. 2003. Pathogens: Raft hijackers. Nat. Rev. Immunol. 3:557-568.

Mayor, S., Rothberg, K. G., and Maxfield, F. R. 1994. Sequestration of GPI-anchored proteins in caveolae triggered by cross-linking. Science 264:1948-1951.

Melkonian, K. A., Ostermeyer, A. G., Chen, J. Z., Roth, M. G., and Brown, D. A. 1999. Role of lipid modifications in targeting proteins to detergent-resistant membrane rafts. Many raft proteins are acylated, while few are prenylated. J. Biol. Chem. 274:3910-3917.

Meyers, B. C., Kozik, A., Griego, A., Kuang, H., and Michelmore, R. W. 2003. Genome-wide analysis of NBS-LRR-encoding genes in Arabidopsis. Plant Cell 15:809-834.

Minami, A., Fujiwara, M., Furuto, A., Fukao, Y., Yamashita, T., Kamo, M., Kawamura, Y., and Uemura, M. 2009. Alterations in detergent-resistant plasma membrane microdomains in Arabidopsis thaliana during cold acclimation. Plant Cell Physiol. 50:341-359.

Miya, A., Albert, P., Shinya, T., Desaki, Y., Ichimura, K., Shirasu, K. Narusaka, Y., Kawakami, N., Kaku, H., and Shibuya, N. 2007. CERK1, a LysM receptor kinase, is essential for chitin elicitor signaling in Arabidopsis. Proc. Natl. Acad. Sci. U.S.A. 104:19613-19618.

Mongrand, S., Morel, J., Laroche, J., Claverol, S., Carde, J.-P., Hartmann, M.-A., Bonneu, M., Simon-Plas, F., Lessire, R., and Bessoule, J.-J. 2004. Lipid rafts in higher plant cells: Purification and characterization of Triton X-100-insoluble microdomains from tobacco plasma membrane. J. Biol. Chem. 279:36277-36286.

Morel, J., Claverol, S., Mongrand, S., Furt, F., Fromentin, J., Bessoule, J.J., Blein, J.-P., and Simon-Plas, F. 2006. Proteomics of plant detergentresistant membranes. Mol. Cell Prot. 5:1396-1411.

Morrow, I. C., and Parton, R. G. 2005. Flotillins and the PHB domain protein family: Rafts, worms and anaesthetics. Traffic 6:725-740.

Nelson, C. J., Hegeman, A. D., Harms, A. C., and Sussman, M. R. 2006. A quantitative analysis of Arabidopsis plasma membrane using trypsincatalyzed (18)O labeling. Mol. Cell Prot. 5:1382-1395.

Neumann-Giesen, C., Falkenbach, B., Beicht, P., Claasen, S., Lüers, G., Stuermer, C. A. O., Herzog, V., and Tikkanen, R. 2004. Membrane and raft association of reggie-1/flotillin-2: Role of myristoylation, palmitoylation and oligomerization and induction of filopodia by overexpression. Biochem. J. 378:509-518.

Neumann-Giesen, C., Fernow, I., Amaddii, M., and Tikkanen, R. 2007. Role of EGF-induced tyrosine phosphorylation of reggie-1/flotillin-2 in cell spreading and signaling to the actin cytoskeleton. J. Cell Sci. 120:395-406

Nürnberger, T., and Kemmerling, B. 2006. Receptor protein kinases-pattern recognition receptors in plant immunity. Trends Plant Sci. 11:519522.

Parniske, M. 2008. Arbuscular mycorrhiza: The mother of plant root endosymbioses. Nat. Rev. Microbiol. 6:763-775.

Pike, L. J. 2006. Rafts defined: A report on the Keystone Symposium on lipid rafts and cell function. J. Lipid Res. 47:1597-1598.

Radutoiu, S., Madsen, L. H., Madsen, E. B., Felle, H. H., Umehara, Y., Grønlund, M., Sato, S., Nakamura, Y., Tabata, S., Sandal, N., and Stougaard, J. 2003. Plant recognition of symbiotic bacteria requires two LysM receptor-like kinases. Nature 425:585-592.

Raffaele, S., Mongrand, S., Gamas, P., Niebel, A., and Ott, T. 2007. Genome-wide annotation of remorins, a plant-specific protein family: Evolutionary and functional perspectives. Plant Physiol. 145:593-600.

Raffaele, S., Bayer, E., Lafarge, D., Cluzet, S., German Retana, S., Boubekeur, T., Leborgne-Castel, N., Carde, J.-P., Lherminier, J., Noirot, E., Satiat-Jeunemaître, B., Laroche-Traineau, J., Moreau, P., Ott, T., Maule, A. J., Reymond, P., Simon-Plas, F., Farmer, E. E., Bessoule, J.J., and Mongrand, S. 2009. Remorin, a Solanaceae protein resident in membrane rafts and plasmodesmata, impairs Potato virus $X$ movement. Plant Cell 21:1541-1555.

Reymond, P., Kunz, B., Paul-Pletzer, K., Grimm, R., Eckerskorn, C., and Farmer, E. E. 1996. Cloning of a cDNA encoding a plasma membraneassociated, uronide binding phosphoprotein with physical properties 
similar to viral movement proteins. Plant Cell 8:2265-2276.

Risselada, H. J., and Marrink, S. J. 2008. The molecular face of lipid rafts in model membranes. Proc. Natl. Acad. Sci. U.S.A. 105:17367-17372.

Robatzek, S., Chinchilla, D., and Boller, T. 2006. Ligand-induced endocytosis of the pattern recognition receptor FLS2 in Arabidopsis. Genes Dev. 20:537-542.

Saito, H., Kimura, M., Inanobe, A., Ohe, T., and Kurachi, Y. 2002. An Nterminal sequence specific for a novel Homer1 isoform controls trafficking of group I metabotropic glutamate receptor in mammalian cells. Biochem. Biophys. Res. Commun. 296:523-529.

Scheiffele, P., Roth, M. G., and Simons, K. 1997. Interaction of influenza virus haemagglutinin with sphingolipid-cholesterol membrane domains via its transmembrane domain. EMBO (Eur. Mol. Biol. Organ.) J. 16:5501-5508.

Schnitzer, J. E., McIntosh, D. P., Dvorak, A. M., Liu, J., and Oh, P. 1995. Separation of caveolae from associated microdomains of GPI-anchored proteins. Science 269:1435-1439.

Schulte, T., Paschke, K. A., Laessing, U., Lottspeich, F., and Stuermer, C. A. 1997. Reggie-1 and reggie-2, two cell surface proteins expressed by retinal ganglion cells during axon regeneration. Development 124:577587.

Shaw, A. S., and Filbert, E. L. 2009. Scaffold proteins and immune-cell signalling. Nat. Rev. Immunol. 9:47-56.

Simons, K., and Toomre, D. 2000. Lipid rafts and signal transduction. Nat. Rev. Mol. Cell Biol. 1:31-39.
Soloviev, M. M., Ciruela, F., Chan, W. Y., and McIlhinney, R. A. 2000. Molecular characterisation of two structurally distinct groups of human homers, generated by extensive alternative splicing. J. Mol. Biol. 295:1185-1200.

Sorek, N., Poraty, L., Sternberg, H., Bar, E., Lewinsohn, E., and Yalovsky, S. 2007. Activation status-coupled transient S acylation determines membrane partitioning of a plant Rho-related GTPase. Mol. Cell Biol. 27:2144-2154.

Stracke, S., Kistner, C., Yoshida, S., Mulder, L., Sato, S., Kaneko, T., Tabata, S., Sandal, N., Stougaard, J., Szczyglowski, K., and Parniske, M. 2002. A plant receptor-like kinase required for both bacterial and fungal symbiosis. Nature 417:959-962.

Widjaja, I., Naumann, K., Roth, U., Wolf, N., Mackey, D., Dangl, J. L., Scheel, D., and Lee, J. 2009. Combining subproteome enrichment and Rubisco depletion enables identification of low abundance proteins differentially regulated during plant defense. Proteomics 9:138-147.

Xiao, B., Tu, J. C., Petralia, R. S., Yuan, J. P., Doan, A., Breder, C. D., Ruggiero, A., Lanahan, A. A., Wenthold, R. J., and Worley, P. F. 1998. Homer regulates the association of group 1 metabotropic glutamate receptors with multivalent complexes of homer-related, synaptic proteins. Neuron 21:707-716.

Zipfel, C., Kunze, G., Chinchilla, D., Caniard, A., Jones, J. D. G., Boller, T., and Felix, G. 2006. Perception of the bacterial PAMP EF-Tu by the receptor EFR restricts Agrobacterium-mediated transformation. Cell 125:749-760 